le mardi 弓̆ juin prochain, à 2 heures précises. Ses travaux se poursuivront dans les journées des mercredi 6 , jeudi 7 et vendredi 8 juin.

Le samedi 9 juin, M. le Ministre de l'Instruction publique et des Beaux-Arts présidera la séance générale de clôture, dans le grand amphithéâtre de la Sorbonne.

Captures et observations biologiques. - M. L. Bleuse signale la capture de Bruchus (Cyphoderes) japonicus Reitt., à Rennes.

Cette espèce, décrite du Japon et trouvée ensuite en Sibérie, avait été rencontrée une fois, accidentellement, a Paris. M. Bleuse l'a prise, le 2.̆ mai, en battant des sarments de Vigne remisés, depuis plusieurs années, dans une maisonnette d'un jardin. Il capturait dans les mêmes conditions, en abondance, Niptus crenatus F abr., Hedobia imperialis L., Pentarthrum. Huttoni Woll., Caulotrupis aeneopictus Boh., etc.

- M. A. Léveillé fait passer sous les yeux de la Société, de la part de M. L. Bleuse, un cadre contenant de remarquables aberrations de Lépidoptères. Ces formes aberrantes, disposées à côté d'exemplaires typiques de chaque espèce, appartiennent aux genres Polyommatus, Lycaena, Melitaea, Epinephele, Macaria, Argynnis, Euchelia et Deiopeia.

Ghangement d'adresse. - M. A. Lécaillon, préparateur de la chaire d'Embryogénie comparée du Collège de France, 7ว̈ bis, rue Monge, Paris.

\title{
Communications
}

\section{Description d'une nouvelle espèce d'Hyménoptère}

(Eupelmus Xambeui)

\section{Par Alfred Giard.}

Eupelmus Xambeui, nov. sp. (fam. Chalcid.). - Eupelmus violace-niger, fronte, scapo antennarum, pleuris femoribusque nigroaeneis; tibiis nigris; tarsis basi albescentibus; terebra longitudine dimidium corporis superante, fusca, albo-annulata; alis nullis. - (Femina).

Long. 4,3 mill. (sans la tarière); tarière 2,ら mill. - Couleur noir violacé avec des reflets vert bronzé sur le front, le scape des antennes, les còtés du thorax, la base de l'abdomen et les pattes. 
Tête plus large que le thorax, à aspect velouté, d'un beau violacé; les joues à reflets verts. Yeux grands, ovales, devenant noirs après la mort. Antennes insérées sur l'épistome, laissant entre leurs bases un espace égal à la distancequi les sépare des yeux, à articulations peu nettes. Scape plus long que le vertex, légèrement courbe (les convexités des deux scapes se touchant en formant un $\mathbf{X}$ ). Flagellum égalant le double du scape et comprenant $\mathbf{1 0}$ articles. Pédicelle obconique, plus court que l'article suivant, les articles 2-7 cylindriques, allant en décroissant lentement; le $8^{\mathrm{e}}$ article formant une massue (triarticulée) excavée à sa partie supérieure.

Prothorax cordiforme, rétréci en avant. Mésonotum présentant une déclivité antérieure et une postérieure; la déclivité antérieure creusée d'un sillon qui se continue sur le prothorax, la postérieure rapide, tronquée, plus courte, remplaçant l'écusson. Lames pleurales bien développées, convexes, à reflets cuivreux.

Abdomen de la longueur du thorax, sessile, trigone, lisse. Base du premier segment bronzée. Ventre caréné. Tarière à valves brunes, pâles dans la partie moyenne. Pattes assez robustes, noires; tarses blancs excepté a leur extrémité qui est noire. Ailes nulles.

Cette nouvelle espèce est parasite de la larve de Gynandrophthalma nigritarsis Lac. ( ${ }^{1}$.

On la trouve dans les environs de Ria (Pyrénées-Orientales) oủ elle est peu répandue. Je la dédie à notre collègue $\mathrm{M}$. le capitaine $\mathrm{X}$ a mbeu qui me l'a communiquée.

L'Eupelmus annulatus Nees, parasite de Cryptocephalus 12-punctatus, est ailé dans le sexe femelle.

\section{Description d'un Orthoptère nouveau de France}

Par J. Azam.

Arcyptera Kheili, n. sp. ${ }^{(2)}$. - Corpus crassiusculum, postice angustatum, colore flavo, castaneo-variegato.

Caput magnum; foveolis verticis contiguis impressis, distincte delineatis. Antennae fuscae, basi testaceae, in ơ capite pronotoque simul sumptis aequales, in \& breviores.

Pronotum supra planum, glabrum, margine postico obtuso-angulato,

(1) Voir X А м в и. Mœurs et métamorphoses des insectes, $10^{\circ}$ mémoire, Lyon, 1899 , p. 36.

(2) J ai signalé cet insecte, sous le nom de Arc. brevipennis Brunner, dans le Bulletin de la Sociélé, 1898, page 370. 


\section{$2 \mathrm{BHL}$ Biodiversity Heritage Library}

Giard, Alfred. 1900. "Description d'une nouvelle espèce d'Hyménoptère (|Eupelmus xambeui|)." Bulletin de la Société entomologique de France 1900, 81-82.

View This Item Online: https://www.biodiversitylibrary.org/item/36399

Permalink: https://www.biodiversitylibrary.org/partpdf/37067.

\section{Holding Institution}

Smithsonian Libraries

\section{Sponsored by}

Smithsonian

\section{Copyright \& Reuse}

Copyright Status: NOT_IN_COPYRIGHT

This document was created from content at the Biodiversity Heritage Library, the world's largest open access digital library for biodiversity literature and archives. Visit BHL at https://www.biodiversitylibrary.org. 